\title{
Dinâmica de produção e comercialização da erva-mate no Rio Grande do Sul, Brasil
}

\author{
Dynamics of production and commercialization of yerba mate in Rio Grande do Sul, Brazil
}

\author{
Sibele Vasconcelos de Oliveira ${ }^{I}$ Paulo Dabdab Waquil ${ }^{I I}$
}

\section{RESUMO}

A produção de erva-mate é uma das atividades não madeireiras que compõe o mercado agroflorestal brasileiro. No Rio Grande do Sul, este segmento é impulsionado pela tradição do consumo do chimarrão. Entretanto, nos últimos anos, observase que o estado gaúcho vem perdendo parcela significativa do mercado nacional, principalmente para o estado do Paraná. Nesse sentido, o presente estudo objetiva compreender a dinâmica produtiva e de comercialização deste produto, a partir da análise do comportamento dos preços pagos aos produtores rurais de erva-mate no Rio Grande do Sul, os preços diretos aos consumidores da erva-mate para chimarrão, além de dados estatísticos relacionados à produção de erva-mate. Evidencia-se que o modelo econométrico realizado para estimar o valor da ervamate, embora indique a existência de associação linear positiva entre as variáveis dependente e independente, é considerado estatisticamente frágil. Ainda, cerca de $80 \%$ das variações no preço do quilograma da erva-mate no varejo de Porto Alegre são explicadas pelas variações no preço da arroba da erva-mate paga aos produtores rurais. Assim, reitera-se a necessidade de análises adicionais para identificar quais fatores exercem maior influência sobre o mercado da erva-mate, no contexto de expansão da demanda nacional e internacional.

Palavras-chave: agronegócios, Ilex paraguariensis, preços agricolas.

\section{ABSTRACT}

The production of yerba mate is one of the nonlumberman forest activities that compose the Brazilian agroforestry market. In Rio Grande do Sul, this segment is propelled by tradition of mate consumption. However, in recent years, it is observed that Rio Grande do Sul state has been losing significant share of the domestic market, mainly to the state of Paraná. In this sense, this study aims to understand the dynamics of production and marketing of this product, from the analysis of the behavior of prices received by farmers of yerba mate in Rio Grande do Sul, prices direct to consumers of yerba mate as well as statistical data related to production of yerba mate. It is evident that the econometric model conducted to estimate the value of yerba mate, while indicating the existence of positive linear association between the dependent and independent variables, is considered statistically frail. Moreover, about $80 \%$ of the variations in the price of the kilogram of yerba mate in retail Porto Alegre are explained by variations in the price of the bushel of yerba mate paid to Rio Grande do Sul farmers. Thus, is reiterated the need for additional analyzes to identify the factors that have an influence on the market for yerba mate in the context of expansion of national and international demand.

Key words: agribusiness, Ilex paraguariensis, agricultural prices.

\section{INTRODUÇÃO}

O agronegócio brasileiro, abrangendo os segmentos de alimentos, fibras e energia renovável, é de suma importância para a economia do país, uma vez que corresponde a cerca de um terço do seu produto interno bruto (PIB), aproximadamente $40 \%$ das receitas de exportações brasileiras, quase $40 \%$ do total de emprego gerados, além de fazer uso de mais da metade da frota nacional de caminhões (MENDES, 2007; CEPEA, 2013).

Em específico, o setor florestal, contemplando os segmentos de processamento de madeira, celulose, papel e móveis, contribui com

\footnotetext{
'Departamento de Administração e Ciências Econômicas, Universidade Federal de Santa Maria (UFSM), Av. Independência, n 3751 , 98300-000, Palmeira das Missões, RS, Brasil. E-mail: sibele_oliveira@yahoo.com.br. Autor para correspondência.

IIPós-graduação em Agronegócios (PPG Agronegócios), Dēsenvolvimento Rural (PGDR), Departamento de Economia e Relações Internacionais (DERI), Faculdade de Ciências Econômicas (FCE), Universidade Federal do Rio Grande do Sul (UFRGS), Porto Alegre, RS, Brasil.
} 
cerca de 5\% do PIB, gera US\$ 3 bilhões em impostos, US\$16 bilhões em exportações e emprega mais de dois milhões de pessoas no Brasil (SBS, 2013). MEDRADO et al. (2005) ressaltam que o impacto do setor florestal na economia brasileira seria ainda maior se, nas estatísticas nacionais, a ele fossem creditados os benefícios das atividades geradoras de produtos não madeireiros, como a castanha-doBrasil, a borracha e o objeto de estudo desta pesquisa: a erva-mate (Ilex paraguariensis).

Apesar da expansão produtiva ocorrida nos últimos anos, o mercado da erva-mate ainda é muito restrito à região sul do Brasil, sendo a base produtiva fortemente apoiada no extrativismo, embora goze do melhor padrão tecnológico entre os produtos florestais não madeireiros e evidente articulação entre os diferentes segmentos que integram a cadeia produtiva (BALZON et al., 2004).

O Rio Grande do Sul, mesmo sendo o estado brasileiro com maior representatividade em termos de consumo e oferta da erva-mate, detendo cerca de $62 \%$ da produção nacional e plantando $43,6 \%$ da área total desta cultura no país, nas últimas três décadas, perdeu participação relativa (IBGE, 2013). Destacando-se pelos altos índices de produtividade, Paraná, Santa Catarina e Mato Grosso do Sul também concentram a produção de erva-mate nacional e vem ganhando espaço neste mercado.

Assim, a partir das mudanças observadas no mercado brasileiro, o presente trabalho objetiva estudar a cadeia produtiva da erva-mate do Rio Grande do Sul através da análise de variáveis relacionadas à produção e comercialização do produto. Para tanto, realizaram-se análises estatísticas e descritivas, contando com a disponibilidade de dados secundários.

\section{MATERIAL E MÉTODOS}

Para analisar as cadeias produtivas agroindustriais, ZYLBERSZTAJN \& NEVES (2000) recomendam a descrição individual de cada elo da cadeia produtiva, o apontamento de suas peculiaridades, bem como a análise dos ambientes institucional e organizacional. Destarte, para o estudo da cadeia produtiva da erva-mate no Rio Grande do Sul, considerou-se o conjunto de atividades econômicas que, articuladas de forma sequencial e progressiva, são responsáveis pela confecção do referido produto, desde as etapas iniciais de elaboração até chegar às mãos dos consumidores finais (ZYLBERSZTAJN \& NEVES, 2000).

Após a identificação e análise dos elos da cadeia produtiva da erva-mate, foram realizadas as coletas de dados secundários, compilados a partir dos sítios eletrônicos da Fundação de Economia e Estatística (FEE, 2014), do Centro de Estudos e Pesquisas Econômicas da Universidade Federal do Rio Grande do Sul (IEPE, 2014), além dos dados disponibilizados pela Organização das Nações Unidas para Alimentação e Agricultura (FAO, 2013) e do Censo Agropecuário de 2006 (IBGE, 2006).

As análises realizadas acerca do mercado e da cadeia produtiva da erva-mate no Brasil e no Rio Grande do Sul apropriam-se dos instrumentais estatísticos de descrição e técnicas de inferência de dados. Para manipulação das informações disponíveis, foi empregado o software Microsoft Office Excel 2007.

Com o intuito da aplicação de técnicas de análise das relações de causalidade, operou-se com as seguintes variáveis, compostas por 192 observações mensais, de janeiro de 1998 a dezembro de 2013:

$\mathrm{Y}=$ Preços pagos pelo consumidor de Porto Alegre pela erva-mate para chimarrão, em reais (R\$) por quilograma (Kg) (IEPE, 2014);

$\mathrm{X}=$ Preços pagos ao produtor rural de ervamate, em reais (R\$) por arroba (FEE, 2014);

Por tratar-se de valores monetários, procedeu-se à atualização dos valores nominais, através do Índice Geral de Preços-Disponibilidade Interna da Fundação Getúlio Vargas, tomando-se como referência o mês de maio de 2014.

\section{RESULTADOS E DISCUSSÃO}

Embora a Argentina seja o maior país produtor de erva-mate em termos mundiais, o Brasil vem ganhando destaque no cenário produtivo e comercial, produzindo atualmente mais de 500 mil toneladas de folha verde. Há ocorrência da produção na Região Sul do país, onde a espécie é considerada nativa. Vale destacar que o maior produtor brasileiro de folha verde de erva-mate é o Rio Grande do Sul, seguido de Paraná, Santa Catarina e Mato Grosso do Sul. Frisa-se que o estado gaúcho possui cinco polos ervateiros, a saber, os polos Planalto Missões, Alto Uruguai, Nordeste Gaúcho, Vale e Alto Taquari, os quais são responsáveis por cerca de $60 \%$ da produção industrial nacional da erva-mate.

Apesar do grande potencial para o uso da matéria-prima em refrigerantes, doces, cosméticos e medicamentos, as folhas desidratadas da erva-mate são majoritariamente destinadas à preparação, por infusão, de um tipo tradicional de chá - denominado chimarrão - consumido na Argentina, Uruguai, Paraguai e nos estados do sul do Brasil. O consumo per capita de erva-mate no Brasil, estimado em 1,2kg 
por ano, é baixo, se confrontado com os números demandados pela Argentina e Uruguai, onde a população consome 5 e $7 \mathrm{~kg}$ por ano de erva-mate seca para a preparação de chás, respectivamente (ABITANTE, 2007).

Com a finalidade de compreender a dinâmica de produção e comercialização da ervamate no Rio Grande do Sul, ao longo deste estudo, discorre-se sobre os principais elos da cadeia produtiva. O fluxograma representado pela figura 1 sintetiza e permite uma melhor visualização do caminho percorrido pelo referido produto, desde o aporte da indústria de insumos e equipamentos até chegar, processado e embalado, ao consumidor final.

Observa-se a realização de cinco tipos básicos de transações na atual configuração da cadeia produtiva da erva-mate no Rio Grande do Sul. A primeira transação, intitulada $\mathrm{T}$, ocorre entre representantes da indústria de insumos e equipamentos e os produtores rurais, sejam eles agricultores familiares ou patronais. Em suma, os insumos, tais como adubos, defensivos, máquinas e equipamentos agrícolas (tratores, implementos e ferramentas), são oferecidos por diversas empresas de origem nacional e internacional.

Embora parte significativa dos ervais explorados no Rio Grande do Sul seja nativo, a implantação dos ervais cultivados se torna possível também a partir da existência de mudas para comercialização. Como grande parte dos produtores não prepara suas próprias mudas, acabam por recorrer aos viveiros comerciais ou a outros produtores rurais especializados (SCHUCHMANN, 2002).
Ainda que não estejam disponíveis dados estatísticos oficiais a respeito da localização e dimensão da produção de insumos e mudas para a cadeia produtiva da erva-mate, estima-se que a grande maioria das organizações situa-se na região Sul do Brasil, próxima aos estabelecimentos agropecuários, onde é desenvolvida a produção primária, e próxima às ervateiras processadoras da matéria-prima erva-mate.

Nesse sentido, segundo dados do Censo Agropecuário (2006), 99,7\% dos estabelecimentos agropecuários com mais de 50 pés de erva-mate existentes em 2006 estavam localizados na região Sul do Brasil, sendo destes 52,3\% localizados no Rio Grande do Sul. Dos 8.228 estabelecimentos rurais com produção de erva-mate no Rio Grande do Sul, cerca de 95,3\% pertenciam aos próprios agricultores, $1,7 \%$ eram arrendados de terceiros, $1,9 \%$ eram ocupados, $0,8 \%$ cultivados na forma de parcerias e $0,3 \%$ eram terras provenientes de assentamentos, ainda sem titulação definitiva.

Conforme Censo Agropecuário (2006), é possível identificar o tamanho dos estabelecimentos agropecuários com mais de 50 pés existentes de ervamate. Dos 15.750 estabelecimentos agropecuários que cultivam erva-mate no Brasil, pelo menos 8.719 possuíam até dez hectares. Na Região Sul e no Rio Grande do Sul, pelo menos 8.915 e 5.083 estabelecimentos agropecuários tem até vinte hectares disponíveis para o cultivo da erva-mate, respectivamente.

Percebe-se que a produção primária da erva-mate é realizada, em grande parte, em estabelecimentos agropecuários com restrita

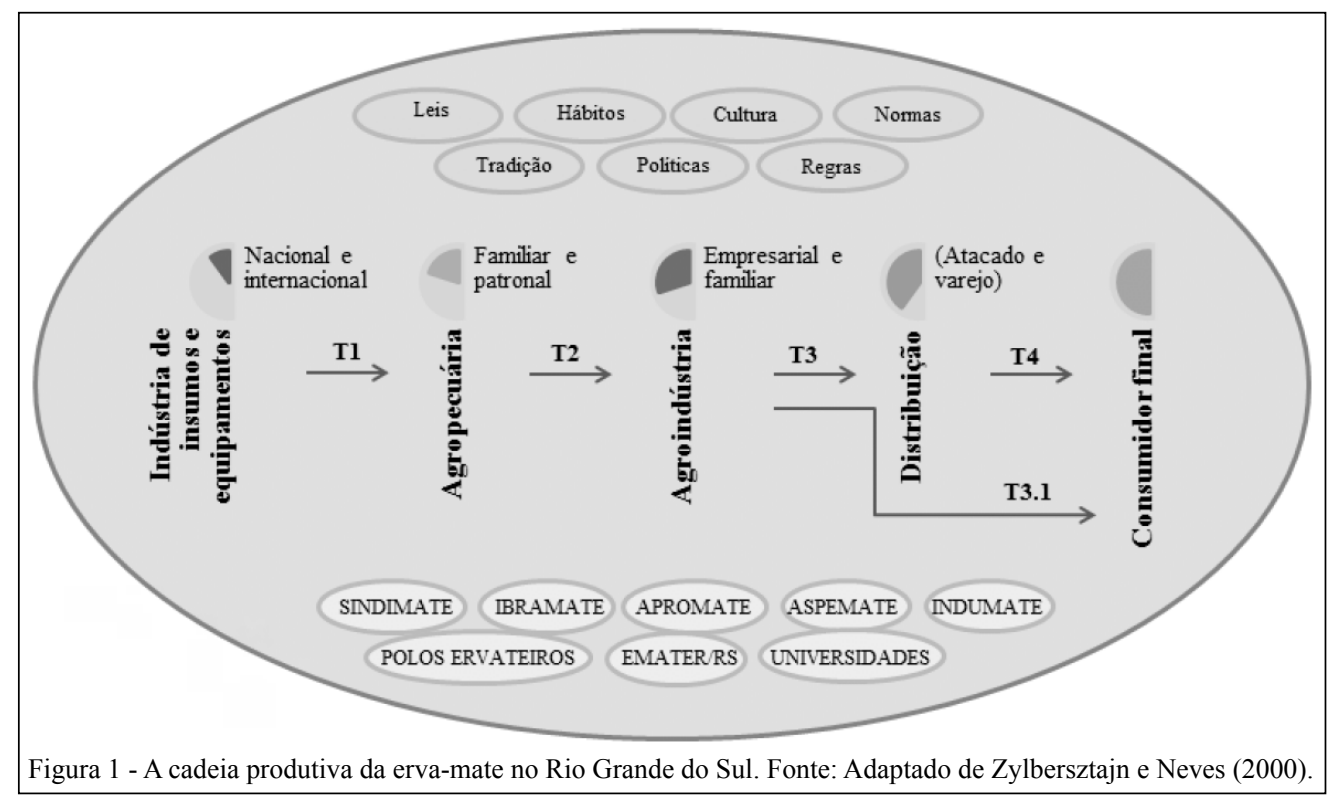

Ciência Rural, v.45, n.4, abr, 2015. 
disponibilidade de áreas cultiváveis. Quanto à mão-deobra, a maioria dos produtores de erva-mate utiliza-se da familiar para a execução das tarefas. Em especial, a erva-mate é desenvolvida em concomitância com outras atividades, uma vez que a terra é utilizada também para plantio em consórcio com outras culturas temporárias (VASCONCELLOS, 2012).

Ainda, de acordo com dados do IBGE (2006), identifica-se a quantidade vendida de ervamate nos estabelecimentos agropecuários com mais de cinquenta pés existentes da planta. Quando se consideram os dados disponíveis para o Brasil e Região Sul, o maior volume de comercialização é realizado por estabelecimentos com até cinquenta hectares, com expressiva representatividade das propriedades com até vinte hectares. No Rio Grande do Sul, cerca de $84 \%$ da quantidade vendida de erva-mate (em toneladas) é proveniente de estabelecimentos com até dez hectares.

Ademais, cita-se a transação realizada diretamente entre agricultores e agroindústrias (T2). Diz-se que a erva-mate passa por duas fases distintas de processamento até chegar ao patamar de consumo na forma de chimarrão, sendo destas, uma realizada pelo produtor rural e outra pela unidade agroindustrial. Chama-se cancheamento o ciclo de preparação da erva-mate que abrange as operações de colheita, sapeco, secagem e trituração. A fase do beneficiamento é desempenhada basicamente pelas agroindústrias e compreende a elaboração final do produto (MACCARI JUNIOR, 2005).

ANTONI (1995) afirma que, no início da década de 1990, havia um grande volume de empresas ervateiras, das quais $70 \%$ eram de micro e pequeno porte. Ainda, a soma do market share das dez maiores empresas atingia de $50 \%$ a $60 \%$ do mercado total. Logo, o segmento industrial da ervamate no Rio Grande do Sul caracterizava-se por ser fragmentado, sem líderes de mercado, onde nenhuma empresa possuía parcela de mercado significativa nem influenciava o resultado da indústria (ANTONI, 1995). Atualmente, estima-se que existam no Rio Grande do Sul aproximadamente 250 ervateiras, inseridas em um mercado com estruturas semelhantes ao do período do final da década de 1990.

Assim, o alto grau de fragmentação da indústria ervateira na região Sul do Brasil e, especialmente, do Rio Grande do Sul, delineia um cenário marcado pela inexistência de organizações com participação dominante no mercado e poucas barreiras de entrada (ANTONI, 1995). Adicionalmente, argumenta-se que economias de escala no processamento industrial de erva-mate não costumam ocorrer, pelo fato de não existirem diferenciais significativos em tecnologia (ANTONI, 1995).
Sobretudo, vislumbram-se duas abordagens estratégicas diretamente relacionadas ao porte das ervateiras. A primeira abordagem estratégica contempla as ervateiras de menor porte, que programam estratégias apoiadas em estruturas de custos menos onerosas que as de maior porte. Asegunda abordagem estratégica é adotada pelas de maior porte, as quais buscam diferenciar-se por meio da fixação da marca, da qualificação do processo de industrialização e da estrutura de distribuição (ANTONI, 1995).

Em complementação, descrevem-se as transações realizadas entre agroindústrias e o setor de distribuição (nomeadas nesta pesquisa de T3) e que compõem as relações comerciais estabelecidas com vistas ao escoamento do produto final aos centros varejistas e/ou atacadistas. Para prevenir riscos sanitários, garantir padrões de qualidade e preservar as áreas com erva-mate, a atual legislação pertinente para o processamento industrial e comercialização normatiza desde a área produtiva até atingir o consumidor final, sendo determinada pelos Ministérios da Saúde e da Fazenda, Instituto Brasileiro do Meio Ambiente e Recursos Naturais Renováveis (IBAMA), entre outros (BALZON et al., 2004).

Como existe também a possibilidade da efetivação de canais de comercialização de nível um, também são configuradas as transações T3.1, realizadas diretamente entre agroindústrias e os consumidores finais. Neste caso, as empresas disponibilizam os produtos em stands de acesso ao público em geral.

As transações T4, realizadas entre o setor de distribuição e consumidor final, caracterizam os canais de comercialização de nível dois ou três, que possuem dois ou três intermediários, normalmente compostos pelo processador da erva-mate, atacadista e varejista.

Sobretudo, destaca-se que a cadeia produtiva da erva-mate está sob influência do ambiente institucional, formado pelo conjunto de leis que regulamentam a produção e comercialização do produto, as regras e costumes que condicionam as preferências dos consumidores e, concomitantemente, delimitam a conduta das empresas atuantes no setor. Além disso, organizações, tais como o Sindicato da Indústria do Mate do Estado do Rio Grande do Sul (SINDIMATE), a Associação dos Produtores de Ervamate (APROMATE), Associação dos Produtores de Erva-mate do Alto Uruguai (ASPEMATE), o Instituto Brasileiro da Erva-Mate (IBRAMATE), a Associação Riograndense de Empreendimentos de Assistência Técnica e Extensão Rural (EMATER/ RS) e Universidades da região, contribuem para o desenvolvimento de pesquisas e campanhas de promoção do produto gaúcho. 
Buscando analisar o comportamento dos preços da erva-mate, operou-se com 192 observações que correspondiam aos preços pagos pelo quilograma da erva-mate no varejo de Porto Alegre e os preços pagos aos produtores rurais do Rio Grande do Sul pela arroba de erva-mate no período de janeiro de 1998 a dezembro de 2013, conforme figura 2 .

Após atualizar os valores nominais dos referidos preços através do IGP-DI (valores em referência ao mês de maio de 2014), constatou-se que a média de preço do quilograma de erva-mate na cesta básica do consumidor de Porto Alegre foi de R\$ 6,20, com desvio padrão amostral de R\$1,12. Já o preço pago pela arroba de erva-mate (folha verde) aos produtores rurais no RS teve média de $\mathrm{R} \$ 7,61$, com desvio padrão amostral de $\mathrm{R} \$ 2,25$.

A tabela 1 apresenta um resumo do modelo estimado para determinação dos preços da erva-mate na cesta básica de Porto Alegre (RS), considerandose dois períodos de defasagem. Esta tabela fornece os valores do $\mathrm{R}$ e do $\mathrm{R}^{2}$ para o modelo que foi calculado. Para esses dados, $\mathrm{R}$ tem um valor de 0,89 e, porque existe apenas um previsor, esse valor representa a correlação simples entre o preço do quilograma da erva-mate no varejo de Porto Alegre (Y) e o preço pago pela arroba de erva-mate ao produtor rural no Rio Grande do Sul (X). O valor de $\mathrm{R}^{2}$ é 0,80 , o que indica que os preços pagos ao produtor rural explicam aproximadamente $80 \%$ da variação no preço da ervamate ao consumidor final.

Pelo valor de $\mathrm{F}$, pode-se afirmar que o modelo de regressão prevê o preço da erva-mate ao consumidor relativamente bem. Em suma, desconsiderando-se os efeitos do coeficiente linear da regressão estimada $-\hat{\mathrm{Y}}=1,93+0,57 \mathrm{X}-$, o aumento previsto no preço da erva-mate para chimarrão ao consumidor final em Porto Alegre, dado o aumento de R \$ 1,00 no preço pago pela arroba do produto aos produtores rurais no Rio Grande do Sul, é de aproximadamente $\mathrm{R} \$ 0,57$.

Logo, infere-se que a supracitada variável é apropriada para o modelo de determinação dos preços pagos pelo quilograma de erva-mate na capital gaúcha. No entanto, ressalta-se a necessidade de inserção de novas variáveis à equação de estimação, já que $20 \%$ das oscilações na variável dependente não são explicadas por X. Pode-se citar, por exemplo, a importância da inserção de variáveis como custos de insumos, de mão-de-obra e de transporte. Vale também a análise da forma como os agentes econômicos se organizam para transacionar, os arranjos de coordenação e os custos de transação inerentes à referida cadeia produtiva.

Ainda, segundo relatório elaborado pela Organização das Nações Unidas para Agricultura e Alimentação (FAO, 2008), alguns fatores afetam diretamente os preços dos produtos agroindustriais, a saber, o crescimento da demanda por alimentos e a mudança da sua estrutura de consumo, as quebras de safra provocadas por oscilações climáticas, os custos crescentes dos combustíveis, entre outros.

Além da influência dos consumidores, dos concorrentes e dos custos de transação, também devem ser levadas em conta a conjuntura econômica, as

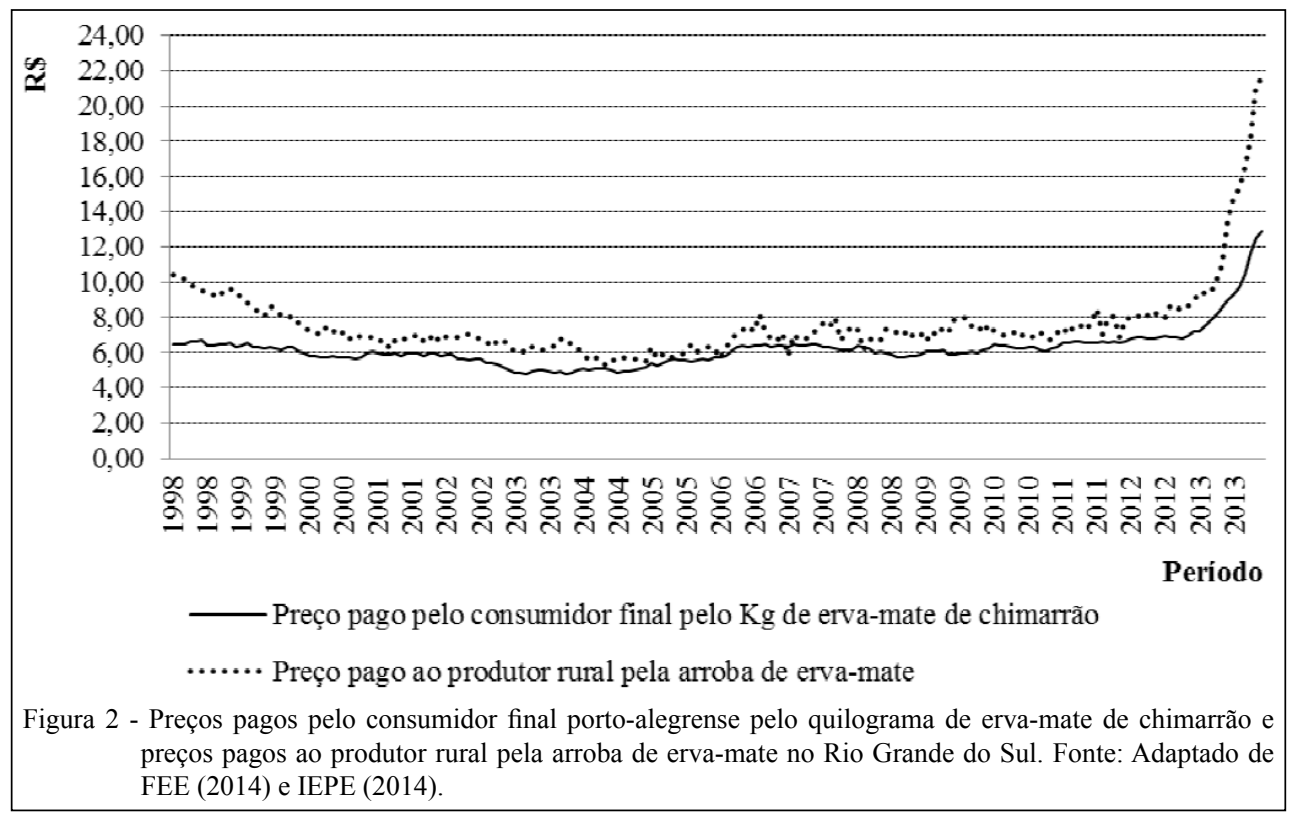

Ciência Rural, v.45, n.4, abr, 2015. 
Tabela 1 - Sumário do modelo econométrico estimado para determinação dos preços da erva-mate no varejo da capital gaúcha.

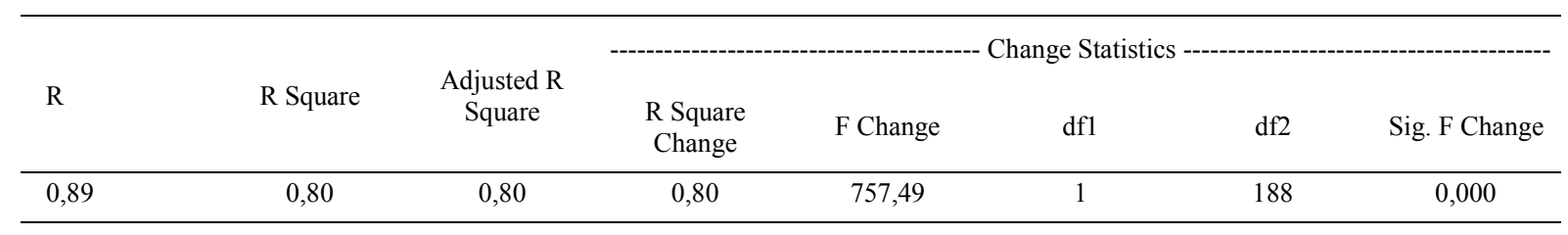

Fonte: Elaborado pelos autores com base em FEE (2014) e IEPE (2014).

diretrizes governamentais, a recessão, inflação e taxas de juros (SARDINHA, 1995). Estes elementos contribuem na precificação dos preços dos alimentos e, embora não tenham sido incluídos no modelo econométrico da presente pesquisa, devem ser analisados.

\section{CONCLUSÃO}

O cultivo da erva-mate compreende um dos sistemas agroflorestais mais antigos e característicos da Região Sul brasileira, ostentando significativa importância socioeconômica e ambiental. Apesar de ser o maior produtor brasileiro, o Rio Grande do Sul vem perdendo parcela de mercado para os estados de Santa Catarina e Paraná. Em suma, fatores de produção, assim como aspectos relacionados à comercialização, influenciam este mercado.

O presente estudo apresentou os resultados de alguns testes estatísticos realizados a partir da manipulação de dados secundários sobre os preços diretos aos consumidores da erva-mate para chimarrão e os preços pagos aos produtores rurais no RS. Evidenciouse que a variável preço pago aos produtores rurais de erva-mate é capaz de determinar aproximadamente $80 \%$ das variações no preço do quilograma de erva-mate disponível no varejo de Porto Alegre.

Destarte, infere-se que a cadeia produtiva da erva-mate no Rio Grande do Sul está inserida em um mercado diferenciado, com características regionais muito marcantes, mais influenciado pelo hábito, pela tradição, do que por variáveis macro ou microeconômicas. Entretanto, afirma-se a importância da análise dos custos de produção, das condições de mercado, entre outros, considerando a complexidade do objeto foco desta pesquisa.

\section{AGRADECIMENTOS}

Os autores agradecem ao Conselho Nacional de Desenvolvimento Científico e Tecnológico $(\mathrm{CNPq})$ pelo apoio à pesquisa, via processo $\mathrm{n}^{\circ} 140825 / 2010-0$.

\section{REFERÊNCIAS}

ABITANTE, A.L. Modelagem dinâmica e análise de um sistema de controle de umidade de folhas de erva-mate em secadores contínuos de esteira. 2007. 78f. Dissertação (Mestrado em Engenharia) - Programa de Pós-graduação em Engenharia, Universidade Federal do Paraná, PR.

ANTONI, V.L. A estrutura competitiva da indústria ervateira do Rio Grande do Sul. 1995. 110f. Dissertação (Mestrado em Administração) - Programa de Pós-graduação em Administração, Universidade Federal do Rio Grande do Sul, RS.

BALZON, D.R. et al. Aspectos mercadológicos de produtos florestais não madeireiros - análise retrospectiva. Revista Floresta, v.34, n.3, p.363-371, 2004. Disponível em: < http://ojs.c3sl.ufpr.br/ ojs/index.php/floresta/article/viewArticle/2422>. Acesso em: 25 abr. 2013. http://dx.doi.org/10.5380\%2Frf.v34i3.2422.

CEPEA (CENTRO DE ESTUDOS AVANÇADOS EM ECONOMIA APLICADA). PIB Agro CEPEA-USP/CNA. Online. Disponível em: <http://cepea.esalq.usp.br/pib/>. Acesso em: 03 mar. 2013.

FAO (ORGANIZAÇÃO DAS NAÇÕES UNIDAS PARA ALIMENTAÇÃOEAGRICULTURA). Soaring food prices: facts, perspectives, impacts and actions required, 2008. Online. Disponível em: <http://www.fao.org/fileadmin/user_upload/foodclimate/ HLCdocs/HLC08-inf-1-E.pdf $>$. Acesso em: 25 mar. 2013.

FEE (FUNDAÇÃO DE ECONOMIA E ESTATÍSTICA). Preços recebidos pelos produtores - EMATER. Disponível em: <http://www.fee.rs.gov.br/feedados/consulta/frame_tabelas. asp? sCaminho=../Tabelas/BIG/1Precos-Emater.html $>$. Acesso em: 10 mai. 2014. Online.

IBGE (INSTITUTO BRASILEIRO DE GEOGRAFIA E ESTATÍSTICA). Censo agropecuário, 2006. Disponível em: $\quad<$ http://www.sidra.ibge.gov.br/bda/tabela/listabl. $\operatorname{asp} ? \mathrm{z}=\mathrm{t} \& \mathrm{o}=11 \& \mathrm{i}=\mathrm{P} \& \mathrm{c}=1181>$. Acesso em: 10 mai. 2014. Online.

MACCARI JUNIOR, A. Análise do pré-processamento da erva-mate para chimarrão. 2005. 215f. Tese (Doutorado em Engenharia Agrícola) - Faculdade de Engenharia Agrícola, Universidade Estadual de Campinas, SP.

MENDES, J.T.G. Comercialização agrícola. Pato Branco: UFPR, 2007. 100p. (Manual didático da disciplina Economia e Desenvolvimento Agrícola).

MEDRADO, M.J.S. A evolução do setor florestal brasileiro no século XXI, 2005. Online. Disponível em: <http://www.agrosoft. org.br/agropag/18698.htm>. Acesso em: 02 mar. 2013.

SARDINHA, J.C. Formação de preço: a arte do negócio. São Paulo: Makron Books, 1995. $146 \mathrm{p}$.

SBS (SOCIEDADE BRASILEIRA DE SILVICULTURA). As plantações de eucalipto no Brasil. Online. Disponível em: $<$ http:// 
www.sbs.org.br/destaques_plantacoesnobrasil.htm>. Acesso em: 01 mar. 2013.

SCHUCHMANN, C.E.Z. Ações para a formulação de um protocolo de rastreabilidade de erva-mate. 2002. $94 \mathrm{f}$. Dissertação (Mestrado em Agronegócios) - Programa de Pósgraduação em Agronegócios, Universidade Federal do Rio Grande do Sul, RS
VASCONCELLOS, F.C.F. Os impactos da criação do Mercosul no mercado de erva-mate no Rio Grande do Sul. 2012. $66 f$. Monografia (Graduação em Ciências Econômicas) -Universidade Federal do Rio Grande do Sul, RS.

ZYLBERSZTAJN, D.; NEVES, M.F. (Org.). Economia e gestão dos negócios agroalimentares: indústria de alimentos, indústria de insumos, produção agropecuária, distribuição. São Paulo: Pioneira, 2000. $428 \mathrm{p}$. 